\title{
EXPLORING THE MORAL DIFFERENCES, BETWEEN INDUSTRIAL DESIGN, ENGINEERING AND ENTREPRENEURSHIP STUDENTS
}

\author{
Mackinzie HAMILTON and Bryan HOWELL \\ Brigham Young University
}

\begin{abstract}
Over the last two years our industrial design programme has been involved in a number of interdisciplinary team projects. We have observed that in successful teams, the education and skills of team members matters less than how the team members interact, structure their work and view their contributions. We believe that there are distinct and innate differences between students in different academic disciplines when it comes to moral positions and these differences in worldview inherently causes friction in interdisciplinary teams. Consequently, we feel that if students could understand these differences extrinsically, they could potentially improve their experience within their interdisciplinary team work.

We ran a pilot study with students from Brigham Young University comparing the industrial design, engineering and entrepreneurship majors using The Moral Foundations Questionnaire (Graham, Haidt \& Nosek, 2008) This survey measures five facets of one's moral position: Care/Harm, Fairness/Reciprocity, In-group/Loyalty, Authority/Respect and Sanctity/Purity.

Results show that designers scored higher in liberal values than their more conservative leaning engineering and business student counterparts. These results support our hypothesis. Understanding the fundamental value differences between disciplinary training should reduce friction and enhance interdisciplinary team communication. This ability to appreciate other mindsets in order to communicate and effectively design with individuals from differing disciplines will be an "essential skill for workers in the coming decades" (Colombo and Grilli, 2005).
\end{abstract}

Keywords: Interdisciplinary teams, communication, design education, interdisciplinary education, product design

\section{INTRODUCTION}

Over the last two years our programme has been involved in a number of interdisciplinary team projects of two or more unique disciplines working cooperatively to define and develop a product. During the winter semester 2018 our industrial designers participated in the European Global Product Realisation Programme (EGPR) programme with City University of London and Budapest University of Technology and Economics. Teams were organised based around disciplinary skillsets including mechanical and electrical engineering, product design and industrial design. These teams also represented individuals with different cultural, primary language skills and geographical backgrounds. The reported outcomes from this project highlight positive product innovation and expanded vision results for the students, but also frustrations with differences in disciplinary language and knowledge assumptions, as well as decision-making capabilities [1]. Based on observations and discussions with the different teams, the coaches concluded that team member communication and relationships were the significant factors in determining whether or not a team felt successful.

Our design programme also participates each year in the Crocker Innovation Fellowship, a twelve-month interdisciplinary entrepreneurship course that combines students from five unique disciplines: physical and digital engineering, industrial design, entrepreneurship and a "wild-card" major. This programme produces teams that build both revenue generating business' as well as teams that slowly disintegrate. In this course students are encouraged to consciously practice "psychological safety" which is the degree 
to which people perceive their team members as supportive when individuals take interpersonal risks such as being seen as ignorant, incompetent, negative or disruptive [2].

\section{INTERDISCIPLINARY TEAM COMMUNICATION}

In addition, the keys to a successful interdisciplinary team are also discussed with students. Primarily that the education, skills and personalities of team members matters less than how the team members interact, structure their work and view their contributions [3]. We also discuss two types of mindsets in the process of decision making: "advocacy" where there are winners and losers, and "inquiry" where the team takes collective ownership. Examples of "advocacy" when compared to "inquiry" can be seen in Table 1 below [4].

Table 1. Two approach's to decision making

\begin{tabular}{|c|c|c|}
\hline & Advocacy & Inquiry \\
\hline Concept of decision making & A contest & Collaborative problem solving \\
\hline Purpose of discussion & Persuasion and lobbying & Testing and evaluation \\
\hline Participants role & Spokespeople & Critical thinkers \\
\hline Patterns of behaviour & $\begin{array}{c}\text { Strive to persuade others } \\
\text { Defend your position } \\
\text { Downplay weaknesses }\end{array}$ & $\begin{array}{c}\text { Present balanced arguments } \\
\text { Remain open to alternatives } \\
\text { Accept constructive criticism }\end{array}$ \\
\hline Minority views & Discouraged or dismissed & Cultivated and valued \\
\hline Outcome & Winners and losers & Collective ownership \\
\hline
\end{tabular}

While it is nice to read about the contrasts between advocacy and inquiry mindsets, they are difficult to manage in practice. Students who have not experienced interdisciplinary projects before have a natural inclination to adopt an "advocacy" mindset over an "inquiry" mindset. The advocacy mindset is not embraced consciously, but is, we believe, reflective of their differences in educational training and disciplinary values. When a young student is trained in their discipline's value system, that is how they come to view the world. They are typically not instructed that there are a multitude of disciplinary methods with alternative points of views or approaches to problems that might be of benefit to a given situation. It is in this lack of understanding or respect for disciplinary differences that we assume a majority of team communication issues stem from.

As recent technological changes continue to emphasise collaboration in organisations [5], there is a growing need to address this lack of skill in management, communication and team-based problem solving exhibited by students in technical fields without sacrificing their in-depth and specialised training [6].

As a result of working through the issues and successes of dozens of interdisciplinary teams on four to twelve month long projects, we suspect that if the students could understand their fundamental value differences based on their intrinsic moral grounding, they would have more empathy for their interdisciplinary counterparts and increase the "psychological safety" of their teams and thus enable improved communication and decision making which are critical in any innovation related career.

Our experience indicates that there are distinct and innate differences between students in the industrial design, entrepreneurship and engineering majors when it comes to moral positions. We hypothesis that: H1- Industrial design students as a group will be the most liberal in moral positions.

$\mathrm{H} 2$ - We propose that engineering students will be on the other end of that spectrum with more conservative moral positions.

H3- Business students, we believe, will fall somewhere in the middle.

We believe these differences in worldview and preference of operation inherently causes friction in interdisciplinary teams and understanding these differences will improve team relationships. 


\section{SURVEY}

Forty undergraduate students from Brigham Young University, primarily juniors and seniors between the ages of 22-25, were sent a link to a digital survey that consisted of 32 questions concerning their individual moral positions. Eleven students from industrial design, engineering and entrepreneurship completed the survey. Seven students did not complete the survey and their results were omitted from the study. The test took an average of ten minutes to complete. The historical data found in the literature surrounding moral values was used to set the baseline.

\subsection{Moral Foundations}

The survey questions were taken from the Moral Foundations Questionnaire [7] which measures the five psychological foundations that determine an individual's sense of morality or "innate ethics." Students were asked to assign a number to the level of relevancy each question played into their consideration of what was 'right' and 'wrong' with 0 being not at all relevant (This consideration has nothing to do with my judgements of right and wrong) and 5 being extremely relevant (This is one of the most important factors when I judge right and wrong). Six questions were used to measure each of these foundations which are defined below:

1- Harm/Care: cherishing and protecting others; the opposite of harm.

Sample question: Whether or not someone suffered emotionally.

2- Fairness/Reciprocity: rendering justice according to shared rules.

Sample question: Whether or not some people were treated differently than others.

3- In-group/Loyalty: standing with your group, family, nation; the opposite of betrayal.

Sample question: It is more important to be a team player than to express oneself.

4- Authority/Respect: submitting/adhering to tradition and authority; the opposite of subversion.

Sample question: Whether or not someone conformed to the traditions of society.

5- Purity/Sanctity: an abhorrence for disgusting things, foods, actions; the opposite of degradation. Sample question: People should not do things that are disgusting, even if no one is harmed.

Individuals' average score from these 32 questions have been shown to correlate to their political ideology. Those who are liberal measure high or place greater importance on the first two facets; Care/Harm and Fairness/Reciprocity. We view this group as having a '2-channel' sense of morality as these two foundations have the greatest weight in perception of right and wrong. Those who are conservative will measure high or place greater importance on the last three facets; In-group/Loyalty, Authority/Respect and Sanctity/Purity, although Care/Harm and Fairness/Reciprocity will still be valued. This profile is called a '5-channel' sense of morality as all five foundations are taken into consideration of perception of right and wrong.

Questions from the Moral Foundations Questionnaire establishes "how" people see the world in fundamentally and inherently different ways. This has significant implications for team-based discourse and relations between a team's individual members, as we are often blind to the different moral foundations of others. Differences in individual behaviours or ideas due to their moral values may be misunderstood and perceived as self-interested or even demonised.

\section{RESULTS}

Our study, while small in sample, produced noteworthy results. We recognise that these results are preliminary and plan on increasing our sample in future studies. Responses for all 32 questions were measured on a five-point scale and then averaged. The results for an average moderate North American as measured by the original moral foundations study was also included and used as a comparative measure between the three disciplines.

The results indicate that there are innate differences between the moral grounding of students measured. Those with liberal ideology will have a greater degree of slope between the first two foundations and the last three, consistent with their 'two-channel' approach to morality. The more extreme this slope the more liberal this person is considered. Conservatives, then, should exhibit a limited or relatively flat slope between the five foundations because of their 'five-channel' morality. Their scores when displayed on a line graph will appear to be flatter. These results are shown in Table 2 and Figure 1. 
Table 2. Score results. Bold letters equal high scores

\begin{tabular}{|c|c|c|c|c|c|}
\hline & $\begin{array}{c}\text { Harm / } \\
\text { Care }\end{array}$ & $\begin{array}{c}\text { Fairness / } \\
\text { Reciprocity }\end{array}$ & $\begin{array}{c}\text { In-group / } \\
\text { Loyalty }\end{array}$ & $\begin{array}{c}\text { Authority / } \\
\text { Respect }\end{array}$ & $\begin{array}{c}\text { Purity / } \\
\text { Sanctity }\end{array}$ \\
\hline Industrial Design & $\mathbf{3 . 6 1}$ & $\mathbf{3 . 5 6}$ & 2.59 & 2.32 & 2.47 \\
\hline Entrepreneurship & 3.12 & 2.97 & 2.92 & 2.62 & 3.26 \\
\hline Engineering & 3.00 & 2.74 & $\mathbf{3 . 0 0}$ & $\mathbf{3 . 0 0}$ & $\mathbf{3 . 3 6}$ \\
\hline $\begin{array}{c}\text { Moderate } \\
\text { North American }\end{array}$ & 3.37 & 3.42 & 2.72 & 2.75 & 2.1 \\
\hline
\end{tabular}

Of the three disciplines, industrial design students had the two highest scores, in Harm and Fairness and also the three lowest scores, in Loyalty, Authority and Purity. Their values swing significantly further than either of the other majors creating a sloped line. Their scores are close to that of a Moderate North American in the first three foundations but show an increased difference in the Authority/Respect and Purity/Sanctity foundations.

Engineering students and their value scores remain the flattest of the three disciplines with little variation between the foundations with the exception of Purity/Sanctity, which was most relevant in their consideration of right and wrong.

Entrepreneurship students also show relative stable scores on the first three foundations but score in between industrial designers and engineers in Authority/Respect. Similar to Engineers, Purity/Sanctity was the most relevant foundation.



Figure 1. Results from Moral Foundations survey. Higher scores indicate increased alignment with the different foundation values

\section{DIscussion}

We can assume, then, that there will be communication and value friction due to the varied individual values and mindsets in interdisciplinary groups. As individuals align with others who think and express themselves in similar ways, they naturally take on an "advocating" mindset, our way of thinking is appropriate [8]. These like-minded individuals may have a greater initial cohesion but also limit their ability to see things in a different way or approach issues from an "inquiring" mindset. Even in organisations where teams are very similar in background and 'forma mentis' in the way they engage 
with and think about change, a "slight cognitive diversity and multidisciplinary reduces their versatility in how to approach a task and their ability to accomplish it [8]." In other words, the differences in moral positioning will likely be a source of innovation and learning but could also decrease productivity and communication if the differences are not understood and respected.

For example, when ideating a new concept friction may occur between engineering students who place a high value on purity and industrial designers who do not. There will be different levels of comfortability exploring ideas that may be seen as radical or 'unnatural' which may limit the diversity and creativity of ideas presented.

Another example may be seen in the prototyping phase. industrial designers who place high emphasis on fairness/reciprocity may be more concerned about accessibility and if the product will work the same way for everyone where engineers, who do not value fairness as much, may be satisfied that the product is functional.

Entrepreneurship students, as they score in between industrial designers and engineers may be able to see things both ways and this could make them better suited with management roles as they help the differing disciplines get along and communicate effectively. However, our current model points that entrepreneurship students align more closely with engineers in values than industrial designers and this may make the middle ground position more difficult to achieve. Where they may be at odds with engineers is in values of authority. Perhaps this mind-set is produced by entrepreneurships emphasis to challenge the status quo and see new opportunities in existing markets.

\subsection{Cultural}

These results raise an interesting question as to where these differences in moral foundations come from. For instance, do students join a major with pre-constructed moral positions and attitudes and are thus drawn to a major with a similar moral culture or does the unique ontology and practices of individual disciplines mould the student and their mind-sets?

These questions also apply to the academic institution each student attends. Do the cultural values of a university also affect its students' moral values? If so, how would these differ from institution to institution?

We found it curious that industrial designers scored below moderate in all foundations but Purity/Sanctity, a foundation shaped by the psychology of disgust and contamination and the "religious notions of striving to live in an elevated, less carnal, more noble way [9]." Could this higher score be influenced by the unique religious homogeneity background of the BYU students, all of whom are members of the same Christian denomination? While our hypothesis played out as predicted in our population, would other homogenous ethnic type groups perform similarly? Would our results change when a general population is introduced to the sample?

\subsection{Limitations}

Some limitations include the small size of our sample which precludes us from testing the statistical significance of the results. Additionally, some preliminary results may be skewed due to the confounding variable of gender. Of the 11 engineering students surveyed, 0 were female while the samples of industrial design and entrepreneurship included 4 females. In particular, we anticipate the moral positioning average of industrial design students will increase when controlled for gender as studies have shown women tend to be more risk-averse than men and place greater importance on harmonious interpersonal relationships [10].

\section{CONCLUSIONS}

As predicted, industrial design students scored higher in both Harm/Care and Fairness/Reciprocity the values of liberal individuals. The entrepreneurship and engineering students scored higher on the Ingroup/Loyalty, Authority/Respect and Purity/Sanctity or the more conservative values.

Also, as predicted, the industrial design students scored on the opposite side of engineering in each foundation of the study while the entrepreneurship students scored in-between the design and engineering students in each foundation except the value of In-group/Loyalty here they scored slightly higher than the engineers.

Based on the preliminary results, $\mathrm{H} 1$ was confirmed. Industrial design students were the most liberal in moral position. $\mathrm{H} 2$ was also confirmed with engineering students scoring more conservative moral 
positions. H3 was also confirmed with entrepreneurship students scoring in between industrial design and engineering students.

We predict that understanding the natural differences in fundamental values between disciplinary training will help students find success in both academic and professional interdisciplinary teams. It is also notable, that our ability to appreciate diverse mindsets and enhance our communication skills with each other will be an essential competence in the coming decades [11]. As students come to understand the moral differences between disciplines, they will hopefully increasingly respect and value their team members which will improve the "psychologic safety" of their team and thus enhance overall performance.

We have observed that people generally think their way of thinking is appropriate. If individuals are committed to improving communication and performance within their interdisciplinary teams, they should step out of their innate self-righteous positions and stop "advocating" for winners and losers, being right and wrong, being for and against. Rather, they should start "inquiring" about truth, from wherever or whatever discipline it might come. As inter-team communication is enhanced hopefully the "collective ownership" of the project will also increase and lead to positive experiential outcome.

\section{REFERENCES}

[1] Kovacevic A., Howell B., Jagadeesh C., Read M., Horak P., Tarnok Z., Hazen G. and Leto A. Application Of "Codeve" Methodology In Transatlantic Student Design Project. In Proceedings of the 20th International Conference on Engineering and Product Design Education (E\&PDE 2018), Dyson School of Engineering, Imperial College, London. 6th - 7th September 2018, pp. 175-180.

[2] Edmondson A.C. Managing the risk of learning: Psychological safety in work teams. International Handbook of Organisational Teamwork, 2002 (London, Blackwell).

[3] Rozovsky J. The five keys to a successful Google team. https://rework.withgoogle.com/blog/fivekeys-to-a-successful-google-team/ [Accessed 2019, 09 March], (2015) 17 November.

[4] Garvin D.A. and Roberto M.A. What you don't know about making decisions. Harvard Business Review, 2001.

[5] Browder R.E., Aldrich H.E. and Bradley S.W. The emergence of the maker movement: implications for entrepreneurship research. Journal of Business Venturing, 2019.

[6] Thursby M., Fuller A. and Thursby J. An integrated approach to educating professionals for careers in innovation. Academy of Management Learning and Education, 2009, 8(3), pp. 389-406

[7] Graham J., Haidt J. and Nosek B. The Moral Foundations Questionnaire (MFQ-30), July 2008

[8] Reynolds A. and Lewis T. Teams Solve Problems Faster When They're More Cognitively Diverse. Harvard Business Review, 2017.

[9] Haidt J., and Joseph C. Intuitive ethics: How innately prepared intuitions generate culturally variable virtues. Daedalus, 2004, 133 (204), pp. 55-66.

[10] Byrnes J., Miller D. and Schafer W. Gender differences in risk taking: a meta-analysis. Psychological Bulletin, 1999, 125(3), pp. 367-383.

[11] Colombo M.G. and Grilli L. Founders' human capital and the growth of new technology-based firms: A competence-based view. Research Policy, 2005, 34(6), pp. 795-816 